\title{
EL SALON DE ABD AL-RAHMAN III. Catálogo de la exposición. \\ (Córdoba. 1995)
}

La exposición del Salón de 'Abd al-Rahman III en Madinat al-Zahrā celebrada en 1995, pretendió exponer el proceso de reconstrucción del mismo, y su funcionalidad histórica, recogiendo la documentación conservada de la época en que se efectuaron los trabajos, así como las conclusiones de diversos estudios sobre él mismo. Ello explica que el catálogo sea en realidad un libro sobre el Salón, en el que no hay "fichas catalográficas", pero que sí recoge una amplísima documentación gráfica, hasta ahora prácticamente desconocida, que ilustra los diversos trabajos, y que no es el menos importante de los numerosos atractivos de la obra que comentamos.

En el texto que abre el volumen, D. Antonio Vallejo, director conservador del Conjunto de Madīnat al-Zahrā, expone el proceso de excavación y restauración seguido por F. Hernández, empleando buena parte del material gráfico original, procedente del propio archivo del arquitecto. Se trata de un texto claro en el que se hace un recorrido por las distintas zonas del Salón, poniendo de manifiesto la amplitud de las investigaciones de D. Félix indicando en cada caso los elementos que había para reconstruir como lo hizo, y en que zonas improvisó más. En este aspecto el autor no oculta las diferencias de criterio que surgieron entre el arquitecto y la Real Academia y otros especialistas como Torres Balbás, reconociendo los evidentes excesos adoptados a la hora de fabricar capiteles para sustituir a los que faltaban, llegando al máximo en la arquería exterior, donde ante la falta de capiteles compuestos recurrió como modelo a uno de la época de al-Hakam II.

Vallejo procura explicar las razones de esta forma de actuar, en la visión integral que F. Hernández tenía de su intervención, y que se diferencia netamente del proceso seguido por él mismo en la restitución de los paneles y frisos decorativos, donde buscó el máximo rigor, considerando que era aquí donde una insuficiente investigación, podía falsificar el sentido del edificio. La descripción de esta parte se realiza de forma pormenorizada, detallando las numerosas dudas y cambios de criterio que el avance en la investigación fue produciendo.

La valoración acerca del conjunto de los trabajos realizados es positiva, pero con el mérito de que, sin caer en los aspectos superficiales de la polémica sobre la restauración, aporta datos precisos acerca del proceso de desarrollo de esta última, que resultaban desconocidos, o de muy difícil acceso, y que permiten enjuiciar mejor lo realizado.

El texto se cierra con unas referencias a los trabajos realizados tras el fallecimiento de Félix Hernández, que resultan quizá demasiado breves, dada la amplitud del cambio de criterio en las formas de trabajo que se produjo.
En conjunto, se trata de un texto fundamentalmente informativo, en el que el autor discute algunas de las soluciones adoptadas, no para pronunciarse a favor o en contra, sino como método para explicarlas, aunque sea evidente su acuerdo en la mayor parte de las ocasiones, y sus dudas en otras. Pero lo que sí defiende el autor con gran contundencia, es el criterio de investigación en profundidad que Félix Hernández siguió, y que luego quedó interrumpido. En definitiva, un texto imprescindible para la historia de la restauración en España y, más directamente, para conocer el Salón, y lo que hay en él de auténtico y de reconstruido.

Los tres artículos siguientes estudian los distintos materiales decorativos existentes: tableros con decoración vegetal, frisos con decoración geométrica y capiteles.

Ch. Ewert ofrece un primer avance del completo estudio que prepara sobre el conjunto decorativo de los paneles parietales. Empieza indicando la diferencia existente entre el planteamiento urbanístico de Madinat alZahrā y el decorativo del Salón. En el primero se mantienen las formas aglutinantes pre-abbasíes de espacios uniformes que constituyen una trama irregular, y que poco tienen que ver con los conjuntos orgánicos de Bagdad o Samarra. Mientras, el conjunto decorativo ofrece, a su juicio, un evidente influjo oriental lo que, unido al tradicionalismo omeya, dió lugar a la creación de un nuevo lenguaje de formas.

La documentación realizada durante décadas, le ha permitido identificar casi mil setecientos elementos y motivos, y poder afirmar que, pese a lo que pudiera deducirse de un vistazo superficial, todos los paneles son diferentes entre sí, aunque en apariencia en todos se imponga un tallo central como eje de simetría, pese a lo cual abundan los elementos asimétricos. Como ejemplo de la complejidad del conjunto, se describen las variantes en cuanto a forma y posición de un pequeño grupo de elementos cerrados con forma de mandorla o corazón, tema por otra parte abundantísimo en el conjunto de paneles. El análisis está realizado con la minuciosidad y precisión que caracterizan los estudios del profesor Ewert, y se cierra con algunas consideraciones sobre los posibles orígenes y la evolución posterior, de los motivos representados.

La decoración geométrica del Salón es bastante menos conocida que la vegetal, quizá por ser menos abundante, y por su posición en los frisos y alfices de los arcos y atraer en consecuencia menos atención de los visitantes. Su importancia es sin embargo evidente en el planteamiento decorativo del conjunto.

Natacha Kubisch ha establecido que todos los temas tienen como base formas geométricas simples que pue- 
den reducirse a cuadrados y hexágonos (formados a partir de triángulos equiláteros), cuyas combinaciones y variaciones dan lugar a doce temas básicos, que se distribuyen por todo el Salón, según una elaborada estructuración. No obstante, esta decoración geométrica aparece unida en algunos puntos a otros elementos complejos como esvásticas, o a motivos vegetales como palmetas, rosetas, etc. A continuación, la autora procura determinar el origen, o los precedentes, de cada uno de los temas, encontrando sobre todo reminiscencias clásicas y abbasíes.

El estudio de los elementos decorativos se completa con el análisis de los capiteles, realizado por P. Cressier, quién comienza por hacer inventario de las once piezas originales aún existentes, de las 42 que adornan el salón, haciendo algunas consideraciones previas acerca de la situación de las mismas, que no es hoy, en todos los casos, la misma que tenían en su origen.

Los capiteles corresponden a los tipos compuesto, corintizante con tres coronas de acanto y corintio, estos últimos situados sólo sobre pilastras. Además de los originales, el autor analiza algunas de las copias existentes, sobre todo aquellas que se realizaron en base a otros fragmentados aparecidos, estableciendo la existencia de diversas variantes, aunque considera que por el caracter de éstas no puede hablarse de diferencias de estilo, sino como máximo de distintos alarifes. Discute el supuesto orientalismo de los capiteles, concluyendo que éste es muy relativo, y que sólo se limita a algunos aspectos menores, que pueden proceder de piezas anteriores a la época islámica.

Por último, analiza la posición de los capiteles en el Salón, a partir de la consideración de que los originales existentes están situados en los lugares que ocupaban antes de la destrucción del edificio. La distinta disposición de los tipos compuesto y corintizante, le lleva a sugerir la existencia de una simetría total respecto al eje longitudinal, y otra simetría, menos común, respecto al eje perpendicular al primero, apuntando la posibilidad de que el espacio cuadrado en que se cruzan hubiese jugado algún papel en el ceremonial califal, concluyendo con algunas sugerencias respecto a las investigaciones que aún son necesarias para profundizar en esta cuestión.

Capítulo aparte merece el estudio de la epigrafía, que en parte puede ser considerada también como elemento decorativo, pero cuya capacidad de información directa la separan del resto, realizando $\mathrm{M}^{\mathrm{a}}$. Antonia Martínez un estudio verdaderamente exhaustivo. La primera parte es un "catálogo" de todas las inscripciones y fragmentos que han podido reconstruirse o que resultan mínimamente significativos, no sólo del salón propiamente dicho, sino las ubicadas también en las estancias inmediatas y en el pabellón frontal, considerando que todo el conjunto forma a fín de cuentas una unidad. De cada una de las inscripciones se indica el soporte, el lugar de aparición, con toda la precisión posible, y la descripción de la cartela. A continuación realiza la transcripción, indicando los aspectos en que puede haber dudas, la traducción, indicando también las dudas o posibles variantes y un estudio epigráfico preliminar del contenido de la misma en el que indica el tipo de escritura, particularidades de algunas letras si las hay, etc.

La segunda parte está dedicada al análisis de los rasgos epigráficos. En ella la autora situa el conjunto de inscripciones dentro del proceso evolutivo de la escritura árabe, demostrando cómo las formas empleadas en este momento en al-Andalus suponen una ruptura con las formas anteriores, y que ello se explica por razones históricas -la proclamación del califato- y por el lugar para el que fueron labradas: el gran salón de ceremonias y su entorno, y que por tanto esta escritura responde a planteamientos de representación oficial del poder. A continuación establece que, aún dentro del mismo estilo, pueden distinguirse tres variantes, empleadas en zonas distintas del salón y su entorno, y que define en función de su mayor o menor austeridad, enumerando después los rasgos epigráficos específicos que presenta cada una de ellas, y que confirman la diferenciación establecida.

En tercer lugar, procede a analizar el formulario empleado en las inscripciones, y las diferencias existentes entre ellas, mostrando la importancia textual de algunos de los epígrafes, indicando que dado el caracter oficial de los mismos, son una clara expresión de cómo el Estado se veía a sí mismo, y de la propaganda que realizaba al respecto. Con esta información la autora remarca la gran cantidad de "préstamos" que los omeyas están tomando en esos momentos de los abbasíes, y profundiza de forma notable en algunos aspectos aún mal conocidos sobre la "estructura de mando" existente entre los responsables de las obras califales, apuntando algunas hipótesis sugestivas.

Capítulo aparte lo constituye el análisis de los títulos con que se designa al Califa. A este respecto son especialmente importantes las inscripciones del friso fundacional del Salón y los del pabellón frontero, en los que aparece el título de Immam, que no vuelve a encontrarse en ninguna de sus inscripciones, lo que la autora intenta explicar mediante un análisis exhaustivo de la titulatura de este Califa.

En conclusión, demuestra cómo, en base a criterios epigráficos, es posible profundizar en algunos aspectos relativos a la estructura y transformaciones del Estado, planteamiento que por desgracia es muy poco frecuente en este tipo de trabajos.

Los dos últimos artículos abordan el problema de las funciones del Salón, y del significado de sus elementos. M. Barceló se centra en el ceremonial omeya que se desarrollaba en el Salón, a partir de los relatos de varias fiestas oficiales de la época de al-Hakam II. Es un texto que se había incluído ya en Estructuras y formas de poder en la Historia, publicado por la Universidad de Salamanca en 1991.

Empieza discutiendo la cuestión de la presencia o evanescencia del Califa, velado en las cortes abbasí y fatimí y "patente" en al-Andalus, encontrando su explicación 
en la existencia de una compleja burocracia, esencialmente fiscal, que hace al Califa remoto e inalcanzable pero al mismo tiempo muy presente en todo el espacio social que domina.

A continuación pasa a describir la distribución de grupos y personas en el interior del salón, según los datos, limitados, proporcionados por los textos, discutiendo las implicaciones políticas y ceremonial de la posición de los individuos o grupos principales, empezando por la ubicación privilegiada del propio Califa, así como de la ausencia de determinados sectores, como la de los directores de la Ceca, indicio de su baja categoria funcionarial, o la de los jefes militares, ya que el ejército no era considerado parte de la estructura del poder califal, sino sólo su sustentador. Por último, analiza la posición otorgada a individuos concretos, como los miembros de la familia de los Tuyibíes, o de los idrisíes, y sus razones o implicaciones.

La presente edición incorpora el color a los dibujos en los que se indica la posición que ocupaban los grupos administrativos y algunos importantes personajes, en el transcurso de diversas ceremonias, aportando una indudable claridad a la exposición. Esto, unido a algunas de las hipótesis que M. Acién formula en el último texto, sugieren que, como indicaba el propio M. Barceló, quizá pueda profundizarse más en este terreno.

En el último texto, M. Acién aborda la cuestión de los paneles decorados, no analizando la decoración, estudio ya realizado por $C h$. Ewert, sino intentando determinar el significado de la misma, con respecto a la función del salón.

En la primera parte del texto, el autor realiza un breve repaso historiográfico a las aportaciones realizadas a lo largo del siglo por los principales estudiosos, haciendo hincapié en los temas (especies vegetales) observados, en la visión de conjunto vista por cada uno (complejidad, yuxtaposición y simetría), y sobre todo en el origen y filiación de los temas apuntado por los diversos autores, estableciendo finalmente una serie de conclusiones en base a las aportaciones más sólidas de cada uno, que suponen una verdadera definición de los rasgos que caracterizan al conjunto decorativo.

En la segunda parte aborda el problema de la funcionalidad de la decoración, aceptando que posiblemente cumplía diversos objetivos, todos ellos difíciles de probar. A la interpretación tradicional como representación del paraíso, apuntada hasta ahora por varios investi- gadores, agrega dos nuevas hipótesis, ambas sumamente originales y sin duda provocadoras, que abren nuevas vías de investigación. En primer lugar sugiere que la decoración pudo estar ligada a la propia representación de la organización del Estado. Enlazando con las propuestas de M. Barceló sobre la existencia de un rígido protocolo en las ceremonias que tenían lugar allí, apunta que la enorme variedad de motivos, organizados por paneles, puede estar haciendo alusión a los distintos grupos y sectores que formaban parte del Estado, cada uno de los cuales se identificaría con un símbolo, haciendo una relación bastante amplia de posibles conexiones, de forma que los paneles lo que estarían marcando es el lugar específico del Salón en el que dichos grupos se situaban.

En su segunda hipótesis, no necesariamente excluyente respecto a la primera, sugiere la posibilidad de una interpretación astrológica de dicha decoración, al establecer una convincente relación entre el contenido del denominado Picatrix, obra dedicada a las diez ciencias, entre las que figuraba la astrología, y los califas omeyas andalusíes, señalando la existencia de algunos pasajes que podrían relacionarse con el sentido de la decoración del Salón, en especial la influencia de los diversos astros, sobre determinadas plantas. Lo que vendría reforzado por el hecho de que mientras los paneles de los zócalos presentan decoraciones vegetales, los frisos situados sobre ellos representan motivos geométricos a base de estrellas. En suma, un texto de gran interés, lleno de ideas que, recurriendo al tópico, pero plenamente aplicable, abre nuevas posibilidades de investigación.

En conclusión, este catálogo rebasa ampliamente la modesta función de acompañante de una gran exposición, a que teóricamente va destinado. Se trata de un libro enormemente ambicioso, que constituye un análisis exahustivo de uno de los grandes monumentos de época islámica, poniendo al día muchos de los elementos que caracterizan el arte califal. Además, supone una notable profundización en la tarea de analizar la imagen que de sí mismo y de su organización interna proporcionaba el Califato de Córdoba en su etapa más brillante, y de demostrar como a ello pueden contribuir elementos que hasta ahora sólo habían sido considerados desde una vertiente estética o textual. Un libro imprescidible para el estudio de esta época. 